\title{
Influence of lower limb dominance and physical activity level on flexibility in healthy subjects
}

http://dx.doi.org/10.11606/1807-5509201800010041

\author{
Tiago NETO* \\ Ana Lisa MELO* \\ Ricardo DAMIÃO* \\ Carla SILVA-BATISTA**
}

\begin{abstract}
The purpose of the present study was to verify the influence of lower limb dominance and physical activity (PA) levels on flexibility in healthy young subjects. Ninety-nine university students (46 males and 53 females) volunteered for this study. Hip flexion range of motion (ROM) during the passive straight leg raise test was used to estimate lower limb flexibility. PA levels were determined by the International Physical Activity Questionnaire-Short Form (IPAQ-SF). The dominant limb of the subjects with high PA levels had higher flexibility values than the dominant and non-dominant limb of the subjects with low PA levels $(p=0.026$ and $p=0.011$, respectively) and the non-dominant limb of the subjects with moderate PA levels $(p=0.038)$. Thus, this investigation shows that lower limb dominance and PA levels have an influence on the flexibility. High flexibility values were observed in the dominant limb of the subjects with high PA levels. Therefore, this information may be useful when planning injury prevention or rehabilitation protocols for subjects with different PA levels and lower limb flexibility asymmetries.
\end{abstract}

KEYwoRDs: Passive Straight Leg Raise Test; Dominant Leg; Non-Dominant Leg; IPAQ-SF.

\section{Introduction}

Flexibility is a physical parameter that enables optimal musculoskeletal function by allowing an adequate range of motion (ROM) in all joints ${ }^{1}$. Poor flexibility may not only influence an athlete's performance ${ }^{2}$, but it is also associated with low back pain $^{3}$ and patello femoral pain ${ }^{4}$. Increasing flexibility is a strategy referred not only by athletes, but also by health and exercise professionals, for musculoskeletal injury prevention 5 . In order to improve the success of the interventions designed to enhance flexibility, it is important to understand which factors may influence the subjects' flexibility levels.

Few studies have analyzed the influence of lower limb dominance $e^{6,7}$ and physical activity (PA) levels ${ }^{8,9}$ on flexibility. Health professionals often use the contralateral limb as a reference for rehabilitation purposes, assuming that they are symmetric regarding to flexibility values. Studies have demonstrated controversial results about flexibility symmetry between lower limbs. For example, RaHnama et al. ${ }^{10}$ did not find differences in hip flexion $\mathrm{ROM}$ values between the dominant and the non-dominant leg in soccer players. On the other hand, WANG et al. ${ }^{7}$ found that flexibility assessed using the passive straight leg raise test (PSLR) was different between lower limbs, in runners. Additionally, it is known that lower limb dominance affects motor control during gait initiation $^{11}$, which can be explained by differences in muscle activation favoring the dominant leg $^{12}$. LANSHAMMAR and RiBOm ${ }^{13}$ also found a significant difference in muscle strength between lower limbs, in healthy women. Taking these investigations into consideration, it seems that lower limb dominance may influence some physical characteristics, such as the flexibility.

Concerning PA, it is known that higher PA levels are related to health benefits, especially in 
a younger population, than low PA levels ${ }^{13}$. One study ${ }^{9}$ reported that healthy subjects (aged 21-43 years) with moderate and high PA levels performed better regarding flexibility of the lower back and hamstrings, compared to the subjects with low PA levels. However, to the best of our knowledge, no study has analyzed how flexibility of the dominant and non-dominant leg may be influenced by PA levels in healthy young subjects.

Previous studies have already shown asymmetries between lower limbs' muscle strength in soccer

\section{Methods}

\section{Study design}

This investigation is a cross-sectional study, where lower limb flexibility (dependent variable) was measured using the goniometric value of the passive straight leg raise test, and compared between-subjects accordingly to their lower limb dominance and physical activity levels (independent variables). players $^{14,15}$ and jumpers ${ }^{16}$. Consequently, it is possible that in subjects with high PA levels who practice regularly these activities, there are asymmetries in flexibility, which may be different from subjects with low PA levels. In this sense, we hypothesized that the dominant limb of the subjects with high PA levels may have higher flexibility values than the non-dominant limb of the subjects with low PA levels. Therefore, the purpose of this study was to investigate if flexibility is influenced by lower limb dominance and PA levels.
BMl - body mass index; SD - standard deviation.

\begin{tabular}{lcccc}
\hline & Mean & SD & Minimum & Maximum \\
\hline Age (years) & 23.6 & 3.5 & 19.0 & 39.0 \\
Height $(\mathbf{c m})$ & 167.8 & 9.5 & 143.0 & 192.0 \\
Weight $\mathbf{( k g})$ & 67.7 & 13.2 & 44.1 & 117.6 \\
BMI $\left(\mathbf{k g} \cdot \mathbf{m}^{-2}\right)$ & 23.9 & 3.3 & 17.6 & 35.3 \\
\hline
\end{tabular}

\section{Procedures}

\section{Anthropometric measurements}

Body weight was measured to the nearest $0.1 \mathrm{~kg}$ using an electronic scale (model ID 1500; Filizola, São Paulo, Brazil). Height was measured to the nearest $0.1 \mathrm{~cm}$ with a stadiometer. Body Mass Index (BMI) was calculated using the values for body weight and height. Lower limb dominance was determined by asking the subjects about their favorite foot when kicking a ball.

\section{Participants}

Ninety-nine subjects (46 males and 53 females) agreed to participate in this study. The subjects' physical characteristics are shown in TABLE 1 . All subjects were university students. Subjects were excluded if they had any musculoskeletal injury of the lower limb or lower back in the past year, and a history of knee or hip surgery. Written informed consent was obtained from all subjects, according to the Declaration of Helsinki.

TABLE 1 - Subjects' physical characteristics $(\mathrm{n}=99)$.

Short version of the International Physical Activity Questionnaire

Physical Activity was determined using the International Physical Activity Questionnaire-short form (IPAQ-SF). This questionnaire is adapted for several countries, and is widely used in PA assessment ${ }^{17}$. The short-form version of the IPAQ considers the daily performed activity, during the last seven days. The outcome is later converted into metabolic equivalent task minutes per week (METs min.wk-1), which can be categorized into three 
PA categories: low, moderate, and high. Low PA represented subjects who did not meet the criteria for moderate- and vigorous-intensity categories (<599 METs min.wk-1). Moderate PA represented moderate- or vigorous-intensity activities achieving a minimum of at least 600 METs min.wk-1, whereas high PA represented achieving a minimum of at least 3,000 METs min.wk-1. The METs values were derived from an IPAQ-SF reliability and validity study ${ }^{18}$.

\section{Flexibility measurements}

Lower limb flexibility was estimated measuring hip flexion ROM during the PSLR test. Due to its passive nature, PSLR eliminates any muscle activity from the quadriceps or hip flexors that could bias the results ${ }^{19,20}$. This test is characterized by a passive hip flexion movement, with the knee in full extension, which is related to hamstrings extensibility ${ }^{21}$. Before data collection, subjects were familiarized with the flexibility assessment protocol. They were instructed to lay supine on an examination table, and to be relaxed, while the examiner moved his lower limb throughout the available hip flexion ROM. The movement was stopped when a firm resistance was felt or when pelvic rotation was observed. After a five minute resting period, data was collected. The same procedure described for familiarization was performed for data collection. When the movement stopped, the final ROM was recorded by an universal goniometer, composed by two plastic arms, each with $30 \mathrm{~cm}$. This is an instrument often used to assess lower limbs' range of motion ${ }^{22,23}$, with excellent reliability $(r=0.91<0.99)^{22}$. This instrument was placed over the greater trochanter, with one arm aligned along the thigh in direction to the lateral femur condyle and the other arm parallel

\section{Results}

The subjects' physical characteristics are shown in TABLE 1. Among the 99 subjects evaluated, $22 \%(\mathrm{n}=22)$ showed low PA levels (mean: 229.6, standard deviation [SD]: 195.2 METs), 51\% ( $\mathrm{n}=51)$ showed moderate PA levels (mean: 1547.4, SD: 600.4 METs), and 26\% $(\mathrm{n}=26)$ showed high PA levels (mean: 4675.8, SD: 1619.8 METs).

The ICC determined for PSLR test was 0.96 for the dominant leg and 0.95 for the non-dominant leg. Regarding lower limb asymmetries, we found that to the table in direction to the mid-axillary line. Two measurements (taken to the smaller unit) were made for each lower limb, and without any prior warm-up. The average of the two flexibility measures was used for analysis, for each lower limb. All measurements were made by the same experienced investigator, who was blinded to the subjects' limb dominance, and also its physical activity level. This PSLR evaluation has been used in other studies ${ }^{24,25}$ to estimate hamstrings flexibility, with Intraclass Correlation Coefficient (ICC) values ranging from 0.92 to 0.97 .

\section{Statistical analysis}

Descriptive statistics (mean values, standard deviation [SD], and 95\% confidence interval $[\mathrm{CI}])$ were used for variable characterization. $G^{*}$ Power 3 software ${ }^{26}$ was used to determine the minimal sample size necessary to detect statistically significant differences between the flexibility values along the IPAQ-SF categories. Using an alpha of 0.05 , and a power level of 0.80 , an effect size of 0.33 was calculated. According to these parameters, a total of 93 subjects was determined by the software as the minimum for this investigation's sample. Reliability of the flexibility assessment was determined by calculating the ICC. To compare the flexibility values between the three PA levels and limb dominance, a mixed model was performed having PA levels (low, moderate, and high) and limb dominance (dominant and non-dominant) as fixed factors, and subjects as a random factor. Whenever a significant $F$-value was obtained, a post-hoc test with a Tukey's adjustment was performed. Data were processed using SAS $9.2^{\circ}$ software (Institute Inc., Cary, NC, USA). Statistical significance was set at $p<0.05$.

$64.7 \%(n=64)$ of the subjects had high flexibility values in the dominant limb and only $35.3 \%(n=35)$ of the subjects had high flexibility values in the nondominant limb. Additionally, 35.3\% ( $\mathrm{n}=35)$ of the subjects had a flexibility asymmetry ratio between lower limbs higher than 10\% (TABLE 2).

There was not a significant limb dominance $\times$ PA levels interaction for the flexibility values $\left(F_{[2,97]}=0.36\right.$, $p=0.699)$. There were significant main effects of PA levels $\left(F_{[2,97]}=5.02, p=0.008\right)$ and limb 
${ }^{*}$ Different from the dominant and non-dominant limb of the subjects with low PA levels of $(p<0.05)$. \# Different from the non-dominant limb of the subjects with moderate PA levels $(p<0.05)$. dominance $\left(F_{[2,97]}=4.40, p=0.039\right)$ for the flexibility values. The post hoc analysis revealed that the dominant limb of the subjects with high PA levels had higher hip flexion ROM (mean: $73.1^{\circ}$, SD: $\left.10.8^{\circ}, \mathrm{CI}: 68.7^{\circ}-7.5^{\circ}\right)$ than the dominant (mean: $63.6^{\circ}, \mathrm{SD}: 9.7^{\circ}, \mathrm{CI}: 59.3^{\circ}$ $67.9^{\circ}, p=0.026$ ) and non-dominant limb (mean: $\left.62.7^{\circ}, \mathrm{SD}: 11.8^{\circ}, \mathrm{CI}: 57.5^{\circ}-68.0^{\circ}, p=0.011\right)$ of the subjects with low PA levels. In addition, the dominant limb of the subjects with high PA levels had higher hip flexion ROM (mean: $73.1^{\circ}$, SD: $\left.10.8^{\circ}, \mathrm{CI}: 68.7^{\circ}-77.5^{\circ}\right)$ than the nondominant limb of the subjects with moderate PA levels (mean: $66.0^{\circ}$, SD: $13.3^{\circ}$, CI: $65.1^{\circ}-68.7^{\circ}$, $p=0.038)$. There were no differences between the flexibility values of the dominant and nondominant limb for the subjects with high PA levels $(p=0.46)$ (FIGURE 1$)$.

TABLE 2 - Lower limb flexibility asymmetries (favoring the dominant or non-dominat limb) distributed by 4 intervals (<5\%; 5-10\%; 10-20\%; >20\%). Values represent number of subjects (n).

\begin{tabular}{lccc}
\hline & $\begin{array}{c}\text { Subjects with higher flexibility in the } \\
\text { non-dominant limb }\end{array}$ & $\begin{array}{c}\text { Subjects with higher flexibility in the } \\
\text { dominant limb }\end{array}$ & Total \\
\hline$<\mathbf{5 \%}$ & 12 & 23 & 35 \\
$\mathbf{5 \% - \mathbf { 1 0 } \%}$ & 14 & 15 & 29 \\
$\mathbf{1 0} \% \mathbf{- 2 0} \%$ & 5 & 22 & 27 \\
$\mathbf{2 0} \%$ & 4 & 4 & 8 \\
Total & 35 & 64 & 99 \\
\hline
\end{tabular}

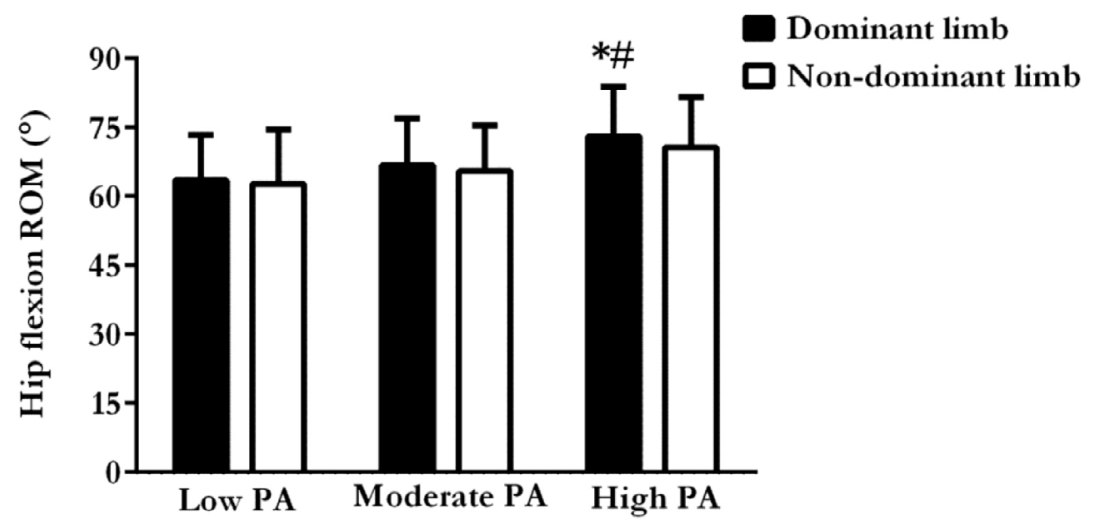

FIGURE 1 - Comparison between the hip flexion range of motion (ROM) values of the dominant and nondominant limb and the International Physical Activity Questionnaire-Short Form's (IPAQ-SF's) physical activity (PA) levels.

\section{Discussion}

The purpose of this study was to determine the influence of lower limb dominance and PA levels on flexibility in healthy subjects. The main findings were that the dominant limb of the subjects with high PA levels had higher flexibility values than the dominant and non-dominant limb of the subjects with low PA levels and the non-dominant limb of the subjects with moderate PA levels (FIGURE 1). Thus, we confirmed our hypothesis.

Few studies have analyzed the influence of lower limb dominance on flexibility. WANG et al. ${ }^{7}$ reported a significant difference $(p<0.05)$ in the hip flexion ROM values between lower limbs, in a sample of 20 runners (aged 18-37 years). Other 
studies that analyzed this phenomenon did not report any influence of lower limb dominance on flexibility ${ }^{6,8,27}$. One possible explanation for our results could be that $73 \%$ of the subjects with high PA level, who took part in this study, reported regular participation in recreational soccer games. The nature of this sport can favor asymmetries to the lower limbs, especially with regard to muscle strength ${ }^{14,15}$. Therefore, it is possible that these muscle strength imbalances driven by the participation in asymmetrical activities may have an effect on the muscle-tendon unit stiffness, which is known to be directly related to muscle extensibility ${ }^{28}$. Considering that we studied healthy subjects, the underlying cause for this asymmetry is not well established, but it is probably related with the lengthening of the posterior thigh, and leg, soft tissues, mainly the hamstrings muscle-tendon unit extensibility, and the subjects' tolerance to stretch ${ }^{27}$. In a clinical setting probably, this difference could not be detected, and therefore it would not be relevant for comparison between lower limbs, or between assessments. However, the emphasis on group data may mask some subjects who have large discrepancies in their flexibility values between lower limbs. In fact, if we look to the asymmetries distributions table, we notice that over one third of the sample shows a difference in flexibility between limbs greater than $10 \%$. In the majority of the cases, this asymmetry percentage represents $5^{\circ}-8^{\circ}$ of hip flexion ROM difference, which is larger than the recently ${ }^{29}$ determined standard error of measurement for the PSLR $\left(2.2^{\circ}-2.6^{\circ}\right)$, and is similar to the minimal detectable difference, also for the PSLR $\left(6^{\circ}-7^{\circ}\right)^{29}$. This means that, even in a clinical setting, the $10 \%$ asymmetry reported in this study should be detected. This information may be particularly useful for health and exercise professionals, when working with individuals recovering from musculoskeletal injuries. There are some studies that refer a benchmark value, known as the leg symmetry index, used for muscle power and strength training in subjects recovering from anterior cruciate ligament injuries ${ }^{30,31}$. This index can vary as low as $80 \%{ }^{30}$ or as high as $95 \%{ }^{31}$. To our knowledge, there are no studies that report a leg symmetry index for lower limb flexibility. Therefore, using the contralateral limb as a reference for rehabilitation, and revaluation processes, may not always be optimal, given that the presence of pre-injury asymmetries may be an assessment's confounding element. However, further research is necessary to clarify the specific effects of lower limb dominance and asymmetrical activities on flexibility.

Considering the influence of the PA levels on flexibility, our results are in agreement with other studies. It has recently been observed that healthy subjects (aged 21-43 years) with moderate $(\mathrm{n}=159)$ and high $(\mathrm{n}=176)$ PA levels reported in IPAQ-SF performed better regarding to the flexibility of the lower back and hamstrings, when compared to the subjects with low PA levels ${ }^{9}$. Similarly, Boyd and VILLA $(2012)^{8}$ assessed PA levels by the Modified Baecke questionnaire in a sample of 40 healthy subjects (mean age: 33 years), and showed a positive and significant correlation $(\mathrm{r}=0.50-0.55, p<0.05)$ between the PSLR values and the PA levels. Thus, our findings demonstrated that not only the lower limb dominance interfere on flexibility values but also the PA levels (FIGURE 1).

The present study has some limitations that should be considered when interpreting our findings. It could be relevant to control which sports were practiced by the subjects who reported higher physical activity levels. As said earlier, there are some sport activities, such as soccer, jumping, or gymnastics, which may favor the use of a preferential limb, and therefore result in flexibility differences between the lower limbs. It would be interesting, in future studies, to analyze the eventual presence of flexibility asymmetries in different sports, and ultimately, to see if this is related to a higher injury risk.

In conclusion, lower limb flexibility appears to be related to limb dominance, and self-reported PA level, and these factors should be taken into consideration by health professionals when planning a rehabilitation program designed to improve ROM, and therefore flexibility. Additionally, injury prevention protocols based on flexibility improvements, should also consider the lower limb dominance variable, specifically when targeted for athletes who participate in sports with an asymmetrical nature for the lower limbs. 


\section{Resumo}

Influência da dominância do membro inferior e do nível de atividade física na flexibilidade de indivíduos saudáveis

0 objetivo deste estudo foi verificar a influência da dominância dos membros inferiores e dos níveis de atividade física (AF) na flexibilidade em sujeitos jovens e saudáveis. Noventa e nove estudantes universitários (46 homens e 53 mulheres) voluntariaram-se para este estudo transversal. A amplitude de movimento (ADM) de flexão do quadril durante o teste passivo de elevação da perna reta foi medida para estimar a flexibilidade dos membros inferiores. Os níveis de AF foram aferidos pela versão curta do Questionário Internacional de Atividade Física (IPAQ-SF). 0 membro dominante dos sujeitos com alto nível de AF apresentou maior valor de flexibilidade do que o membro dominante e não dominante dos sujeitos com baixo nível de $\operatorname{AF}(p=0,026$ e $p=0,011$, respectivamente) e do que o membro não dominante dos sujeitos com moderado nível de $\operatorname{AF}(p=0,038)$. Assim, este estudo demonstrou que a dominância do membro inferior e o nivel de AF influenciam nos valores de flexibilidade. Maiores valores de flexibilidade foram observados na perna dominante dos sujeitos com alto nivel de AF. Desta forma, esta informação pode ser relevante para o planejamento de protocolos de prevenção de lesões ou de reabilitação em indivíduos com niveis distintos de AF e assimetrias de flexibilidade nos membros inferiores.

Palavras-chave: Teste Passivo de Elevação da Perna Reta; Membro Inferior Dominante; Membro Inferior Não-dominante; IPAQ-SF.

\section{References}

1. Sainz de Baranda P, Ayala F. Chronic flexibility improvement after 12 week of stretching program utilizing the ACSM recommendations: hamstring flexibility. Int J Sports Med. 2010;31(6):389-96.

2. Alonso J, McHugh MP, Mullaney MJ, Tyler TF. Effect of hamstring flexibility on isometric knee flexion angle-torque relationship. Scand J Med Sci Sports. 2009;19(2):252-6.

3. Somhegyi A, Ratko I. Hamstring tightness and Scheuermann's disease. Am J Phys Med Rehabil. 1993;72(1):44.

4. Witvrouw E, Lysens R, Bellemans J, Cambier D, Vanderstraeten G. Intrinsic risk factors for the development of anterior knee pain in an athletic population. A two-year prospective study. Am J Sports Med. 2000;28(4):480-9.

5. Saragiotto BT, Di Pierro C, Lopes AD. Risk factors and injury prevention in elite athletes: a descriptive study of the opinions of physical therapists, doctors and trainers. Braz J Phys Ther. 2014;18(2):137-43.

6. Youdas JW, Krause DA, Hollman JH, Harmsen WS, Laskowski E. The influence of gender and age on hamstring muscle length in healthy adults. J Orthop Sports Phys Ther. 2005;35(4):246-52.

7. Wang SS, Whitney SL, Burdett RG, Janosky JE. Lower extremity muscular flexibility in long distance runners. J Orthop Sports Phys Ther. 1993;17(2):102-7.

8. Boyd BS, Villa PS. Normal inter-limb differences during the straight leg raise neurodynamic test: a cross sectional study. BMC Musculoskelet Disord. 2012;13(1):245.

9. Silva-Batista C, Urso R, Silva AL, Bertuzzi R. Associations between fitness tests and the international physical activity questionnaire-short form in healthy men. J Strength Cond Res. 2013;27(12):3481-7.

10. Rahnama N, Lees A, Bambaecichi E. Comparison of muscle strength and flexibility between the preferred and non-preferred leg in English soccer players. Ergonomics. 2005;48(11-14):1568-75.

11. Dessery Y, Barbier F, Gillet C, Corbeil P. Does lower limb preference influence gait initiation? Gait Posture. 2011;33(4):550-5.

12. Valderrabano V, Nigg B, Hintermann B, Goepfert B, Dick W, Frank C, et al. Muscular lower leg asymmetry in middle-aged people. Foot Ankle Int. 2007;28(2):242-9.

13. Lanshammar K, Ribom EL. Differences in muscle strength in dominant and non-dominant leg in females aged 20-39 years: a population-based study. Phys Ther Sport. 2011;12(2):76-9.

14. Garber C, Blissmer B, Deschenes M, Franklin B, Lamonte M, Lee I, et al. American College of Sports Medicine position stand: quantity and quality of exercise for developing and maintaining cardiorespiratory, musculoskeletal, and neuromotor fitness in apparently healthy adults - guidance for prescribing exercise. Med Sci Sport Exerc. 2011;43(7):1334-59. 
15. Ergün M, Işlegen C, Taşkiran E. A cross-sectional analysis of sagittal knee laxity and isokinetic muscle strength in soccer players. Int J Sports Med. 2004;25(8):594-8.

16. Luk H, Winter C, O’Neill E, Thompson B. Comparison of muscle strength imbalance in powerlifters and jumpers. J Strength Cond Res. 2014;28(1):23-7.

17. Craig CL, Marshall AL, Sjöström M, Bauman AE, Booth ML, Ainsworth BE, et al. International physical activity questionnaire: 12-country reliability and validity. Med Sci Sport Exerc. 2003;35(8):1381-95.

18. Fogelholm M, Malmberg J, Suni J, Santtila M, Kyröläinen H, Mäntysaari M, et al. International Physical Activity Questionnaire: validity against fitness. Med Sci Sport Exerc. 2006;38(4):753-60.

19. Ayala F, Baranda PS de, Croix MDS, Santonja F. Criterion-related validity of four clinical tests used to measure hamstring flexibility in professional futsal players. Phys Ther Sport. 2011;12(4):175-81.

20. Gajdosik RL, LeVeau BF, Bohannon RW. Effects of ankle dorsiflexion on active and passive unilateral straight leg raising. Phys Ther. 1985;65(10):1478-2.

21. Gajdosik R, Lusin G. Hamstring muscle tightness: reliability of an active-knee-extension test. Phys Ther. 1983;63(7):1085-90.

22. Rolls A, George K. The relationship between hamstring muscle injuries and hamstring muscle length in young elite footballers. Phys Ther Sport. 2004;5:179-87.

23. Witvrouw E, Danneels L, Asselman P, D’Have T, Cambier D. Muscle flexibility as a risk factor for developing muscle injuries in male professional soccer players: a prospective study. Am J Sports Med. 2003;31(1):41-6.

24. Castellote-Caballero Y, Valenza MC, Martín-Martín L, Cabrera-Martos I, Puentedura EJ, Fernández-de-Las-Peñas C. Effects of a neurodynamic sliding technique on hamstring flexibility in healthy male soccer players. A pilot study. Phys Ther Sport. 2013;14(3):156-62.

25. Hall T, Beyerlein C, Hansson U, Lim HT, Odermark M, Sainsbury D. Mulligan traction straight leg raise: a pilot study to investigate effects on range of motion in patients with low back pain. J Man Manip Ther. 2006;14(2):95-100.

26. Faul F, Erdfelder E, Lang A, Buchner A. G*Power 3: a flexible statistical power analysis program for the social, behavioral, and biomedical sciences. Behav Res Methods. 2007;39(2):175-91.

27. Ayala F, Sainz de Baranda P, De Ste Croix M, Santonja F. Comparison of active stretching technique in males with normal and limited hamstring flexibility. Phys Ther Sport. 2013;14(2):98-104.

28. Marshall P, Cashman A, Cheema B. A randomized controlled trial for the effect of passive stretching on measures of hamstring extensibility, passive stiffness, strength, and stretch tolerance. J Sci Med Sport. 2011;14(6):535-40.

29. Neto T, Jacobsohn L, Carita A, Oliveira R. Reliability of the active knee extension test and the straight leg raise test in subjects with flexibility deficits. J Sport Rehabil. 2015;24(4):e-pub.

30. Holsgaard-Larsen A, Jensen C, Mortensen NHM, Aagaard P. Concurrent assessments of lower limb loading patterns, mechanical muscle strength and functional performance in ACL-patients: a cross-sectional study. Knee. 2014;21(1):66-73.

31. Thomeé R, Neeter C, Gustavsson A, Thomeé P, Augustsson J, Eriksson B, et al. Variability in leg muscle power and hop performance after anterior cruciate ligament reconstruction. Knee Surg Sports Traumatol Arthrosc. 2012;20(6):1143-51.

\section{Conflict of interest}

The authors declare no conflict of interest.

\section{Acknowledgments}

The authors thank Pedro Reis and João Ramos for their contribution during data collection. The authors also want to thank to all the subjects who participated in this study.

ADDRESS

Tiago Neto

Physiotherapy Department

Lunex University

50 Avenue du Parc des Sports, 4671 - Differdange - Luxembourg

e-mail: netogtiago@gmail.com
Submitted: 03/08/2015 1st. Review: 03/11/2015 2nd. Review: 12/02/2016 Accepted: 06/04/2016 
